\title{
On the trail of 007: media pilgrimages into the world of
}

James Bond

Reijnders, S. (2010). On the trail of 007. Media pilgrimages into the world of James Bond.

Area 42: 369-377. 


\section{On the trail of 007: media pilgrimages into the world of}

\section{James Bond}

The first law for a secret agent is to get his geography right.

- Ian Fleming (1965)

In the Indian Ocean off the coast of southern Thailand lies an island that was originally known as Ko Tapu. For generations, the people of this island supported themselves by fishing, growing rice and tapping rubber. But in the middle of the 1970s, this way of life changed drastically. EON Productions - the production company responsible for the James Bond franchise - had seen the potential of the picturesque island as a location for The Man with the Golden Gun (1974). When this film, which was popular around the world, appeared, Ko Tapu became internationally famous almost overnight. Within a few years, it had become one of the top tourist attractions in Thailand, complete with James Bond tours, teeshirts and assorted souvenirs. 'James Bond Island,' as it is now known, attracts over a thousand visitors a day.

The history of James Bond Island is not unique; there are other locations that are known entirely or partly thanks to their appearance in a James Bond film or novel. Over a period of more than four decades, twenty-four James Bond films have appeared, resulting 
in an extensive, international network of 007 locations. The tourist industry makes full use of the power of these locations to attract tourists. Visit Kent (a tourism promotion organization in the English county of Kent) has published brochures that call Kent 'James Bond Country' and state that 'Nowhere are you closer to James Bond and his creator!'. Numerous James Bond tours are also on offer elsewhere, for example in London (the 'James Bond Cab Tour' and the 'James Bond Walk') and the Bahamas (the 'James Bond Movie Site Beginners Tour'). In London there are special James Bond stag parties. During these events, the prospective bridegrooms - dressed as James Bond - are offered Martinis, a speedboat trip on the Thames or an evening in a casino with their male friends.

A simple but intriguing question is, Why? Why do people travel to places that are associated with the James Bond films and books? In order to answer this question, an interview study was conducted in the autumn of 2008 among Bond fans who had recently visited one or more of the locations from the 'world of Bond'. This paper presents an analysis of these interviews, offering an insight into the cultural practices and experiences of these James Bond tourists. First, though, I discuss briefly the theoretical background to this article and the methodology I adopted.

\section{Media pilgrimages}

Strictly speaking, James Bond tourism is not an isolated phenomenon. In recent years an increasing number of studies have investigated the attraction for tourists of locations that are associated with popular films, books, songs and TV series. For instance, attention has been paid to the 'Manhattan TV Tour' in New York (Torchin 2002), X-Files fans in Vancouver (Hills 2002), pilgrimages to Strawberry Fields (Kruse 2003), the 'set jetters' 
who visit New Zeeland because The Lord of the Rings was filmed there (Tzanelli 2004; Beeton 2005), Japanese Harry Potter tourists in the United Kingdom (Iwashita 2006) and the 'Inspector Morse Tour' in Oxford (xxxxx 2009b).

One of the most authoritative studies of this phenomenon was based on the studio tour of the set of Coronation Street at Granada Studios in Manchester (Couldry 2003). According to Couldry, these travels should be defined as 'media pilgrimages', which are comparable to traditional, religious pilgrimages. He bases this interpretation on Victor and Edith Turner's classic statement (1978) that a pilgrimage is more than just a physical journey: it is also a symbolic journey towards certain central values of society. But whereas Turner and Turner are still working in a structuralist tradition, and base their ideas on the prior existence of fundamental values, Couldry adopts a post-structuralist approach, analysing how these rituals do not mirror but actively construct certain values.

Couldry argues that in the case of a media pilgrimage, these values are implicitly connected to the symbolic authority of the media. Thus, media pilgrimages are not only a physical journey to a location that is important in the context of a particular media story, but also represent a symbolic journey, during which the distance between the 'ordinary world' and the 'media world' is collapsed for a moment. But this entails a certain cost: making a distinction between the 'ordinary world' and the 'media world,' and then creating the impression that this boundary can be crossed, albeit only briefly, reinforces and naturalizes the symbolic authority of the media. In this way, says Couldry $(2003,28)$, media pilgrimages function first and foremost as a 'rite of institution'.

Couldry's work makes an important contribution to the study of media pilgrimages by showing how these rituals contribute to the symbolic authority of the media. At the 
same time, his approach tends to overemphasize the role of the media. By interpreting media pilgrimages solely as rites of institution, the media are placed in a central and dominant position. To avoid this media fallacy and reduce the danger of reductionism, I think we should take into account the cultural embeddedness of media pilgrimages. In my view, this can be solved by acknowledging the way the authority of the media is related to other power structures, such as gender and ethnicity. This paper takes the first step along that path, by focusing specifically on the relation between media pilgrimages and masculinity.

James Bond offers an ideal point of departure for analysing these gender dimensions. After all, masculinity takes a central role in the narratives of Bond. As Ian Fleming wrote in an essay $(1963,14)$, he created Bond for "warm-blooded heterosexuals in railway trains, airplanes or beds'. Over the years, Bond has been the topic of many academic studies. According to the authors of these studies, James Bond is a paragon of manliness: physically strong, hard working, and in control of women and technology (Eco 1966; Bennett \& Woollacott 1987; Zani 2006). The scientific literature views Bond as a unique combination of two classic male ideals: the playboy and the hard-working, selfsacrificing puritan. The female characters - the 'Bond girls' - are either traditional victims or emancipated women, who need to be 'corrected' or 'reconquered' by Bond (Bennett \& Woollacott 1987, but see Bold 2005). According to critics, this sexual ideology is combined with an imperialist, neo-colonial ideology: Bond travels around the world protecting the interests of the British Empire, receiving support in this from local 'boys' with a different coloured skin (Bennett \& Woollacott 1987; Baron 2003; Chapman 2007, 
24-29). In other words, the Bond world is an exotic, feminine landscape that needs to be roamed through and mastered.

The overt presence of sexual ideology in the Bond texts suggests that the theme of gender is part and parcel of media pilgrimages into the world of Bond. To put it the other way round, it is at least plausible to suppose that these media pilgrimages influence the gender identity of the people concerned. If we take into account my critical additions to Couldry's approach, this leaves us with the following question: how is the symbolic boundary between inside and outside the media in the cultural practice of Bond pilgrims related to the reconstruction of dominant gender discourses from the Bond texts?

\section{Method}

Twenty-three semi-structured in-depth interviews were conducted. The respondents were recruited via a call for participants that was placed on eight Bond websites. ${ }^{2}$ With the exception of one woman and one child, all the respondents were grown men. The majority of respondents came from the United States, England and the Netherlands; there were also respondents from Canada, Germany, Japan, Russia and Sweden.

What all the respondents had in common was their pronounced interest in James Bond. All of them regularly visited James Bond websites and were prepared to spend an extended period talking about their interest in Bond. Partly because the respondents came from all over the world, it was decided to conduct the interviews by phone. The interviews had a semi-structured format: although a list of questions was used, it did not dominate the interview. The respondents were given an active role in setting the tone of their interviews, so that each respondent had the chance to present his or her own perspective (Bryman 2004, 
314-232). The goal of these interviews was threefold: to reconstruct the journey (How did you prepare for the journey? What did you do step by step?); to determine the inner experience of the Bond pilgrims (How did you experience being there? What made it special? What do you like about Bond?); and to discuss the overall meaning of the pilgrimage (With whom did you share your experience? How do you recall and reflect upon your journey?). In other words, although the interviews were partly aimed at gathering concrete information about the journey, the interview setting created a stage for discussing and reflecting upon the respondents' experiences. In that sense, the interview method was based on a combination of 'what' and 'how' questions (Silverman 2002, 95101).

The results of the interviews are presented in the following sections. The design of the analysis is more or less based on the classic phases of the pilgrimage, in line with the work of Turner and Turner (1978) and Arnold van Gennep (1909). First, I describe how the Bond fans withdraw from their everyday lives in order to go and search for the world of Bond. The second, 'liminal' phase concerns those moments at which the Bond fans are actually on location. Some respondents describe this experience as 'being inside the world of Bond'. Lastly, during the 'post-liminal' phase, the Bond fans return home, where they recall and sometimes commemorate their journeys.

\section{Across the bridge}

'Earth has nothing to show more fair,' wrote William Wordsworth in 1802, in praise of the view from Westminster Bridge. 'Ships, towers, domes, theatres, and temples lie / Open unto the fields, and to the sky.' More than two centuries later, the view from Westminster 
Bridge is still imposing, with the Palace of Westminster to the west and the London Eye to the east. To this day, the bridge is still a popular 'Kodak spot' for the never-ending stream of tourists.

But not all these tourists look at the view that Wordsworth praised: some of them lean over the bridge railing and train their eyes downwards, closely studying the pillars of the bridge. This is because in a scene from the Bond film Die Another Day (2002), James Bond (played by Pierce Brosnan) crosses Westminster Bridge, goes down a stairway and opens a door hidden in a pillar of the bridge. Behind the door is an abandoned underground station, where Bond finds M. waiting for him with instructions for a new assignment.

The door in Die Another Day is a well-known literary technique, comparable to the rabbit hole in Alice in Wonderland, the window in Peter Pan or the train platform in Harry Potter. In all these works of fiction, the everyday, often rather boring life of the protagonist is contrasted with a rich fantasy world. The protagonist only has to open a door, accidentally fall down a rabbit hole or discover some other magical entryway to attain that other, beautiful, exciting world.

The difference between the door in Die Another Day and many of its literary predecessors is that this door actually exists - or rather, there is a door in one of the pillars of Westminster Bridge, it was used for the shoots in Die Another Day and it can still be located today. This makes the door more than just a literary technique. The place is likewise a lieu d'imagination: a physical point of reference to an imagined world (Xxxxx 2009a). The fact that there is no abandoned underground station behind the door, and no secret entrance to MI6 headquarters, and that it actually leads to a broom closet, does little to reduce the attraction that this location has for James Bond fans. The fact that the door 
can be seen and touched is enough to justify the journey to Westminster Bridge. As Delmo said in his interview, actually touching this door and taking a picture of it, allowed him to make Bond's world 'more realistic' and tangible. ${ }^{3}$

The quest for an imagined world is not unique to the Bond pilgrimage. In fact, this quest is part and parcel of all media pilgrimages. In the words of Turner and Turner (1978), every pilgrim goes through a 'pre-liminal phase' in which he/she steps out of his/her everyday life and gains access to holy or magical locations. What is most striking about the Bond pilgrimage is not so much the quest itself as the way in which the quest is performed and described by its practitioners. For the James Bond fans, the symbolic difference between the 'normal world' and the 'world of Bond' is first and foremost a difference that needs to be traced and analysed meticulously, in an almost technological way.

This comparison is carried out to the last detail. For example, many James Bond fans work with an extensive photo collection - and this requires a degree of preparation. Before the trip, the relevant film is watched a few more times, with special attention paid to scenes filmed on location. When an identifiable location is spotted, the video or DVD is paused and the stills are printed or photographed. Once the fan is on location, this collection of stills is compared in detail to what the fan encounters there. Pictures are taken, ideally from the same angle as in the film and under comparable weather conditions. Later, these pictures - a combination of movie stills and amateur photos - are put in folder, creating a mirror-image photo collection.

In addition to collecting concrete similarities and discrepancies, the respondents are also intrigued by the underlying process, namely how EON Productions uses existing locations to create a fictional world: 
And then you ask yourself when you're standing there... You really ask yourself, how in God's name did they find this? Or what made them choose this particular alley?... You start looking at totally different things - how did they make this? How does this fit together? It's more the things behind the scenes...

- Martijn

The older Bond films are especially admired, since they were made at a time when producers did not have access to advanced technology and were dependent on existing locations. The use of digital technology in the more recent films is considered a corrupting factor rather than an additional challenge:

With virtual graphics and computer mediated imagery, you can pretty much make anybody, anywhere, do anything. That kind of spoils the fun of filmatography. For me, that's rubbish. I like to get up there and see how it was done - let my imagination climb up there and think about the whole technical aspects of filming those old scenes...

The interest in film technology, the making of detailed photo collections and the desire to collect and identify all the locations, together create a picture of an activity that has a strongly masculine character. The contrast with the findings of early studies of media pilgrimages among the primarily female fans of Beatrix Potter (Squire 1993, 1994) and Inspector Morse (Thomas 1995; xxxxx 2009b) is great. While Potter fans are eager to visit 
the souvenir shops - where the classic Beatrix Potter tableware brings family memories to the surface - James Bond fans hit the trail with professional camera equipment and use detailed photographic comparisons to reach authoritative conclusions about the 'reality quotient' of specific scenes.

Seen from the perspective of the Bond fans, the tracking and localizing of film locations offers the opportunity to indulge in a pursuit and to display certain masculine traits. After all, technology and rational thinking are traditionally defined as masculine realms (Connell 1995, 164-184). At the same time, these masculine traits also legitimize the pursuit itself. As is known from many fan studies, fans are often confronted with negative stereotypes of fandom: they are seen as hysterical fanatics, caught in the spell of superficial media entertainment (cf. Jenkins 1992, 15; Hills 2002, 166-170). The same applies to Bond fans, who talk about being laughed at by friends and family members for their 'childish' hobby. By turning their media pilgrimage into a technological and rational quest for knowledge, these fans try to legitimize their hobby as a masculine thing to do.

\section{To the source}

Making a comparison between the 'Bond world' and the 'real world' and determining the underlying production process are not the only motivating factors for the Bond fans: many want not only to see and photograph the door from Die Another Day, but also to open it and enter the world that lies behind it. The respondents spoke of wanting to get 'as close as possible to the story' and to 'make a connection': 
I feel like that by actually visiting the location, it feels more real. It's like, not only have you seen it on your TV in your living room, but you have experienced it and walked in the same place... It creates a sort of casual, realistic connection to something that already has, I guess, a fond place in my heart.

Actually being at the location that featured in the Bond film, and being able to see, hear, smell and feel the surroundings, makes the world of 007 tangible and close by, and brings it to life:

You go to this alley or that hotel and you get some feeling. Inside you have an experience that you cannot buy for money or anything. In your heart and brain you feel you and Bond have something in common....

- Gunter

This feeling is intensified by performing certain routines at the location. Most of the respondents said that while at the location they assume a Bond pose, with their index fingers representing pistols. But acting out the James Bond role is not limited to photographing certain poses. The remaining experiences of the journey were also described in a way that presents a clear analogy to the visual imagery and events in a typical Bond adventure. The respondents talked about 'tracking' and 'chasing' locations, making ready use of the knowledge of 'local informants' (almost always taxi drivers). The more prosperous respondents rent an Aston Martin and retrace the route that Bond drove in one 
of the films or novels. Locations that are difficult to reach, whether due to their remoteness or because access is forbidden, are seen as a particular challenge. Just like their beloved super spy, Bond fans wait for dusk and then, under the cloak of darkness, climb over that one fence or cross that one field to get close enough to take that one unique shot through a telephoto lens. In other words, Bond's spying activities are used as the ideal blueprint for organizing their own tourist activities, creating a convergence between the spy experience and the tourist experience (cf. Bratich 2009).

These acts of mimicry were interpreted differently among the respondents. Some respondents emphasized the hilarious and carnivalesque character of their acts. They laughed about the impersonifications and described the whole setting in notions of play. Seen from the perspective of ritual theory, these respondents can be labelled 'pretenders': participants who downplay the ritual structure and prefer to celebrate the loose and playful elements of the ritual (Rooijakkers 2000, 190-194). It is striking that in this case, the one and only female respondent positioned herself as a 'pretender' pur sang:

It was only sort of a joke [...] We used the James Bond activities as a loose direction. [...] So for us it wasn't, erm, too obsessive, it was more quirky fun things that we could do in our day.

Other respondents - the so-called 'believers' - emphasized the more serious elements of these acts of mimicry. They liked to talk about the deeper meanings they attach to their involvement, echoing notions from Clifford Geertz' work on 'deep play’ (Geertz 1972). 
Through their mimetic proceedings, these respondents aim to 'bring Bond to life'. They talked about the feeling of having entered this 'other' world, if only temporarily:

It's like a kick, you know. You're at least here, now. You're on the same track.... You're not just watching it, but you are inside the film.

These experiences seem to comply with the characteristics of the liminal phase of a ritual, as described in the works of Turner and Turner (1978) and van Gennep (1909). This is the phase in which the Bond pilgrims are the furthest from their everyday lives and momentarily seem to merge into an 'anti-structure', experiencing oceanic feelings of freedom.

Notwithstanding these feelings of freedom, the experienced anti-structure cannot be interpreted as operating fully outside the social-cultural world and its inherent ideologies. Anti-structures do not mirror fundamental values but actively participate in the construction of social reality. Thus, the question arises: what values form the basis of the Bond pilgrimages?

In the first instance, the interviews suggest that there is no single answer to this question. Bond's moral world seems to vary from respondent to respondent. To his fans, James Bond is first and foremost an 'open' character, which allows each fan to give his/her own interpretation (cf. Bennett \& Woollacott 1987). Still, a number of values recurred in the interviews. Ideas of manliness are central to most respondents' view of Bond. He is 
seen as a 'strong' and 'brave' man, who is able to surround himself with fast cars, weapons and beautiful women. Bond is 'good at what he does' and lives an 'independent life'.

This perception of Bond's character agrees with previous studies that have looked at the sexual ideology of James Bond. Scholars interpret Bond as a paragon of manliness a paragon with a strongly conservative and hetero-normative disposition (Chancellor 2005, 79-83). The respondents recognize this sexual ideology, but without explicitly condemning it. On the contrary, these fans - the majority of whom are white, heterosexual men - adore the character of Bond. Exploring his world and repeating some of his actions affords these fans the opportunity to embody and act out a certain idealized masculinity:

A license to be what you like. That is part of the fun. Fantasy and fun are involved, [but it's also about] the emulation you put in your life. Thinking this particular way, dressing that way, enjoying the items, the cars...

By performing Bond, these fans perform and thereby reconstruct a specific masculinity (cf. Buchbinder 1998; Edley \& Wetherell 1995). Of course, this kind of gender performance comes with a price. In everyday life, at work or at home, a totally different kind of masculinity is often expected. In his book Masculinities (1995), Robert William Connell describes how men in contemporary societies are confronted with a role model of masculinity that is hard to live up to. On television and in films they are presented with the picture that they need to be sexy, powerful, smart and strong, all at the same time. According to Connell, many men have difficulty reconciling this 'hegemonic masculinity' 
with the social position they occupy in the context of family, friends and work. Elaborating on Connell's work, some authors have spoken of finding a balance between a 'mediated masculinity’ and 'lived reality' (e.g. Beynon 2002, 64-68).

The Bond locations occupy a special position in this difficult balancing act. They provide the respondents with an opportunity to physically embody a mediated masculinity - if only briefly. What makes these experiences meaningful is their physical nature. As Henri Lefebvre (1991) argued, every ideology needs a geophysical foundation, where individual power relations can be physically delineated. In line with Lefebvre, one could speak of the Bond locations as material-symbolic sources of masculinity, where the individual's sexual identity can be rediscovered, delineated and reinforced.

Despite this, everyday life is often less far away than one would think, even at these liminal landscapes of Bond. This is certainly the case of respondents who combine their Bond pilgrimage with a normal holiday with their partner. They need to adjust their desire to those of their spouse:

Look, I need to plan things a bit with my partner. The first thing is she doesn't care about James Bond, not one bit... She always thinks I'm crazy... When we visit Bond locations, there's also something...uh ... 'cul-tu-ral' or something like that to see. I mean, then we can visit James Bond locations one day and then we can go shopping for the next four days.

\section{Places of memory}


Once they are home, the pictures are combined to create the previously-mentioned mirrorimage photo albums, generally complemented with written travel accounts. In most cases, these accounts are posted on one of the many James Bond fan websites. As Gary said in his interview, fans like to 'brag to those who care.' By sharing their travel experiences with others (primarily other male Bond fans), they are able to demonstrate their status as connoisseur in a society of like-minded fans, thus creating 'fan cultural capital' (Fiske 1992):

You've been doing this for years. After a while, of course, a lot of people start to think of you as sort of an expert in that area. I really want to be able to show that in one way or another.

These travel accounts also serve more personal purposes. Many respondents talked about regularly going through all the photos and reviving their memories. Having being present at the scene and having acted out certain poses or scenes has not only brought the film to life, but has also brought back memories that are related to the film. It is, in other words, a process of reminiscence - of retrieving 'forgotten' memories by repeating actions from the past. Just as singing old songs from one's schooldays can rekindle one's memories of those days, visiting locations that feature in Bond films can bring back memories that are attached to early viewing experiences.

This process does not appear to the same degree for all Bond films: the first encounter with the Bond phenomenon takes pride of place. The respondents gave extensive 
descriptions of how they went to the cinema, usually as boys in their early teens, to see their first Bond film. Travelling to the locations from that film - twenty, thirty or even forty years later - brings back memories from that period of the respondent's youth, and also brings to mind the symbolic distinction between the boy and the man:

When you get older, you get more sheltered. But there is a bit of boyishness left. Dressing that way, enjoying the items, car and gadgets [recaptures] a bit of boyishness. Being a boy $\operatorname{again} . .$.

-Paul

A temporary return to the dreams of youth permits a fresh look at the present:

For me he [Bond] just got absolutely everything that a boy growing up in the seventies and eighties, you know, would aspire to be like. [Now] I can do all the things I want to do. Live the James Bond lifestyle because I've worked hard, you know, graded by the number of professional qualifications. That was my inspiration behind wanting to go.... To do the things that he has done, even when you know it's in a fictional world.

These quotations present an experiential world in which the symbolic distinction between boy and man is linked to a dichotomy between imagination and reality. Although it is not always expressed so explicitly, this experience is common to many of the other respondents. Many people view childhood as a period full of fantasy, but one that is closed, in sharp 
contrast to the grown-up man's world in which career and social competition take first place. Visiting Bond locations appears to offer respondents a progressive experience: first, the dichotomies are identified on the basis of a detailed comparison; second, this affords them the possibility of transcending these dichotomies, so that the imagination can rule, if only briefly, within the restrictions of the adult world. In other words: for these men, Bond makes fantasizing a legitimate activity.

Of course, this process of reminiscence leads not only to autobiographically oriented recollections. Another kind of memory can also be evoked. The Bond films serve as important time-documents for many fans. Their memories of the 1960s are inextricably linked with the imagery in films like From Russia with Love (1963) and On Her Majesty's Secret Service (1969). Visiting these Bond locations now in 2009 makes them aware of the passage of time:

When you're at the spot, you can see what things have changed since the sixties and seventies... Things have really changed, you know.

By being present on location and comparing the current landscape with the old film stills, the respondents can see what has changed over the years - not only in themselves and in Bond, but also in the wider cultural landscape of which they and Bond are part.

\section{Conclusion}


In 1953, James Bond made his first trip to the French Riviera, with the assignment to beat the Russian spy Le Chiffre at the Casino Royale. Since then, Bond has travelled the world with regularity. Many of these locations have developed into tourist hot-spots. As tourists follow in Bond's footsteps, the common processes of commoditization and commercialization have accompanied them. In some cases one can speak of a short-lived hype - a period of two or three years in which the locations are literally inundated with tourists. Other locations retain their attractive power and develop over the years into regular destinations for a band of faithful Bond fans. So far, it is largely unknown which factors play the determining role in this process. Other questions also remain unanswered, such as what effects this wave of tourists has on the local community, or what the future of this type of tourism will be.

This paper focused on the perspective of the tourists, by reconstructing and analysing their experience of the Bond pilgrimage. Previous studies have shown the importance of the symbolic difference between 'inside' and 'outside' the media for the experience of media pilgrimages. Media pilgrimages are said to support the symbolic authority of the media; by honouring locations from the media, one honours the media as an institution.

From the twenty-three interviews with Bond fans, it appears that the Bond pilgrimage confirms the importance of this symbolic difference. During the Bond pilgrimage, the differences between everyday life and the world of Bond are carefully traced and analysed; this is followed by a temporary and carnivalesque transgression of this inside/outside border. Some respondents emphasized the ludicrous elements of these acts, 
while others appeared to take the Bond pilgrimage much more seriously. However, both groups acknowledge the importance of the above-mentioned symbolic difference.

At the same time, this symbolic difference cannot be seen apart from the underlying theme of masculinity that runs through all the phases of the Bond pilgrimage. For example, Bond fans described the pre-liminal phase - in which pilgrims leave their everyday lives and approach their destinations - in highly technological and rational terms. For them, the confrontation between 'inside' and 'outside' the media is primarily a technologically driven enterprise, focused on gathering photographic 'evidence' and identifying the 'reality quotient' of specific scenes. Comparing the world of Bond with the 'real world' offers them the possibility to perform certain masculine traits, while, vice versa, these masculine characteristics also legitimize the pilgrimage as a whole, in line with the fans' attempts to counter dominant stereotypes of 'fanatic' and 'childish' fans.

The liminal phase is focused on bringing Bond 'to life'. The respondents overwhelmingly white, middle-aged heterosexual men - talked about temporarily 'going into' the world of Bond. This process is encouraged by performing certain mimetic actions, such as assuming a Bond pose, taking the same route as Bond did or performing complete scenes. They admire Bond for his decisiveness and his wanderlust, and view him as a model of masculinity. By walking in the footsteps of 007, the respondents repeat and reexperience the narrative development, and are able to sneak inside James Bond for a moment. For them, the Bond world serves as a place where they can portray and embody an idealized masculinity, namely the 'mediated masculinity' of Bond.

Lastly, in the post-liminal phase, the Bond fans return home and record their experiences in mirror-image photo collections - iconic interpretations of the real/reel 
dichotomy. Some fans decide to upload their collections to one of the many websites for James Bond fans in order to share their experiences with like-minded people, primarily other male Bond fans. By showing their photographs and commenting on the technological skills of the production team, these fans consolidate their status and authority. Having the final say about the 'truth' of a certain scene or production detail is indeed a valuable trait in the James Bond fan hierarchy.

Thus, although the symbolic difference between 'inside' and 'outside' the media plays a structuring role in the proceedings of the Bond pilgrimage, viewed from the perspective of the fans, this inside/outside dichotomy is inseparably intertwined with notions of masculinity. When it comes to the point, the former functions as a ritual set of instruments for the latter. By tracing, analysing and finally transgressing the symbolic boundary between everyday life and the world of Bond, these fans are able to experience a Turnerian 'anti-structure,' a moratorium on everyday life, in the company of an imagined hero. Mimicking Bond at the very place where he was sitting, running, fighting or making love, enables them to recollect the roots of their own masculinity, to refresh it and to define it.

More in general, these conclusions show the importance of analysing media pilgrimages in a wider cultural context. The authority of the media does not come about in a vacuum, but is tightly interwoven with other power configurations. In addition to gender, dimensions of class and ethnicity will also need to be explored in further research. Equally important are those media pilgrimages that seem to subvert existing power configurations. While the Bond pilgrimage tends to reconstruct patriarchal notions of masculinity, other media pilgrimages might actually challenge these values, operating as Bondian 
'counterspies'. The concept of media pilgrimage, placed in its proper cultural context, promises to be a valuable tool in analysing these processes.

\section{References}

Baron C 2003 Doctor No: Bonding Britishness to racial sovereignty in Lindner $\mathbf{C}$ ed The James Bond phenomenon. A critical reader Manchester University Press, Manchester $135-50$

Beeton S 2005 Film induced tourism Channel View Publications, Clevedon

Bennett T and Woollacott J 1987 Bond and beyond. The political career of a popular hero MacMillan Education, London

Bold C 2005 'Under the very skirts of Britannia': re-reading women in the James Bond novels in Lindner $\mathbf{C}$ ed The James Bond phenomenon. A critical reader Manchester University Press, Manchester 169-83

Bratich J Z 2009 Spies like us. Secret agency and popular occulture in Packer J ed Secret agents. Popular icons beyond James Bond Peter Lang, New York 133-62

Bryman A 2004 Social research methods Oxford University Press, Oxford

Buchbinder D 1998 Performance anxieties: re-producing masculinity Allen \& Unwin, Sydney

Chancellor H 2005 James Bond: the man and his world John Murray, London

Chapman J 2007 License to thrill. A cultural history of the James Bond films Tauris, London

Connell R W 1995 Masculinities Polity Press, Cambridge 
Couldry N 2003 Media rituals. A critical approach Routledge, London

Couldry N 2008 Pilgrimage in mediaspace. Continuities and transformations Etnofoor 20 $63-74$

Eco U 1966 The narrative structure in Fleming in Eco U and Buono O D eds The Bond Affair Macdonald, London 76-85

Edley N and Wetherell M 1995 Men in perspective: practice, power and identity. Prentice-Hall, London

Fiske J 1992 The cultural economy of fandom in Lewis L A ed The adoring audience Routledge, London 30-49

Fleming I 1963 How to write a thriller Books and Bookmen 5 14-15

Fleming I 1965 The man with the golden gun Jonathan Cape, London

Geertz C 1972 Deep play: notes on the Balinese cockfight Bobbs-Merrill, Indianapolis Gennep A van 1909 Les rites de passage. Étude systématique des rites. Picard, Paris Iwashita C 2006 Media representations of the UK as a destination for Japanese tourists: popular culture and tourism Tourist Studies 6-1 59-77

Jenkins H 1992 Textual poachers: television fans and participatory cultures. Routledge, London

Hills M 2002 Fan cultures. Routledge, London

Kruse R J 2003 Imagining Strawberry Fields as a place of pilgrimage Area 35 154-62

Lefebvre H 1991 The production of space Blackwell, Oxford xxxxx 2009a Places of the imagination. An ethnography of the TV detective tour Cultural Geographies (accepted for publication) 
xxxxx 2009b Watching the detectives. Inside the guilty landscapes of Inspector Morse, Baantjer and Wallander European Journal of Communication 24-2 165-82

Rooijakkers G 2000 Vieren en markeren. Feest en ritueel in Dekker T, Roodenburg H and Rooijakkers G Volkscultuur. Een inleiding in de Nederlandse etnologie SUN, Nijmegen 173-230

Silverman D 2002 Interpreting qualitative data. Methods for analysing talk, text and interaction Sage, London

Squire S J 1993 Valuing countryside: reflections on Beatrix Potter tourism Area 24 5-10

Squire S J 1994 Gender and tourist experiences. Assessing women's shared meanings of Beatrix Potter Leisure Studies 13 195-209

Thomas L 1995 In love with Inspector Morse: feminist subculture and quality television Feminist Review 51 1-25

Torchin L 2002 Location, location, location. The destination of the Manhattan TV Tour Tourist Studies 2-3 247-266

Turner V and Turner E 1978 Image and pilgrimage in Christian culture: anthropological perspectives Columbia University, New York

Tzanelli R 2004 Constructing the 'cinematic tourist'. The 'sign industry' of The Lord of the Rings Tourist Studies 4 21-42

Zani S 2006 James Bond and Q: Heidegger's technology, or 'You're not a sportsman, Mr. Bond' in South J B and Held J M James Bond and philosophy. Questions are forever Open Court, Chicago 173-86 
${ }^{1}$ This research was financed by a Veni grant from the Netherlands Organisation for Scientific Research. Further thanks go to the respondents for their cooperation in this study, to Vincent Crone, Niels van Doorn and Rob Leurs for their help searching for Bond locations, and to Linda Duits and various other colleagues for their comments on earlier versions of this article.

${ }^{2}$ A call for participants was placed on the following websites in the autumn of 2008 :

http://commanderbond.net/, http://www.mi6.co.uk, http://www.007magazine.co.uk/,

http://www.jamesbondnederland.org, http://www.universalexports.net/, http://www.007.info/, http://www.007nl.net/cms/ and http://www.ajb007.co.uk.

${ }^{3}$ All quotations are from the interview transcripts, unless otherwise noted. These transcripts are available from the author. 